\title{
Characterization of airway inflammation in patients with COPD using fractional exhaled nitric oxide levels: a pilot study
}

This article was published in the following Dove Press journal: International Journal of COPD

16 July 2014

Number of times this article has been viewed

\author{
James F Donohue' \\ Nancy Herje ${ }^{2}$ \\ Glenn Crater ${ }^{2}$ \\ Kathleen Rickard ${ }^{2}$ \\ 'Department of Medicine, University \\ of North Carolina School of Medicine, \\ Chapel Hill, NC, USA; ${ }^{2}$ Aerocrine, Inc., \\ Morrisville, NC, USA
}

Objective: To characterize fractional exhaled nitric oxide (FeNO) levels that may be indicative of Th2-mediated airway inflammation in patients with chronic obstructive pulmonary disease (COPD).

Methods: This single-visit, outpatient study was conducted in 200 patients aged 40 years and older with COPD. All patients underwent spirometry and FeNO testing. COPD severity was classified according to the Global initiative for chronic Obstructive Lung Disease (GOLD) 2010 guidelines.

Results: Patients who participated in the study had a mean age of $63.9 \pm 11.3$ years and a mean smoking history of $46 \pm 29$ pack years. Patients had a mean forced expiratory volume in 1 second $\%$ predicted of $53.9 \% \pm 22.1 \%$. The percentage of patients classified with COPD severity Stage I, II, III, and IV was $13 \%, 40 \%, 39 \%$, and $8 \%$, respectively. In addition, according to current procedural terminology codes, $32 \%$ of patients were classified as mixed COPD/asthma, $26 \%$ as COPD/emphysema, and $42 \%$ as all other codes. The mean FeNO level for all patients was $15.3 \pm 17.2$ parts per billion (ppb). Overall, $89 \%$ of patients had a FeNO $<25 \mathrm{ppb}, 8 \%$ had a FeNO $25-50 \mathrm{ppb}$, and $3 \%$ had a FeNO $>50 \mathrm{ppb}$. The percentages of patients with FeNO in the intermediate or high ranges of FeNO were greatest among patients with mixed COPD/asthma (intermediate, 11.5\%; high, 6.6\%) compared with COPD/emphysema (intermediate, $8 \%$; high, 0 ) and all other codes (intermediate, 6.3\%; high, 1.3\%).

Conclusion: Increases in FeNO were identified in a subset of patients with COPD, particularly in those previously diagnosed with both COPD and asthma. Since FeNO is useful for identifying patients with airway inflammation who will have a beneficial response to treatment with an inhaled corticosteroid, these data may have important implications for the management of COPD patients.

Keywords: fractional exhaled nitric oxide, chronic obstructive pulmonary disease, asthma, inhaled corticosteroids

\section{Introduction}

Airway inflammation is now recognized as the central mechanism in the pathogenesis of asthma and its symptoms. It is also recognized that asthma can co-exist with chronic obstructive pulmonary disease (COPD), particularly in older adults, a condition labeled the "overlap syndrome" or "Asthma COPD Overlap Syndrome (ACOS)". ${ }^{1}$ Asthma itself may, in fact, be a risk factor for the development of COPD. ${ }^{1}$ While airway inflammation in COPD is generally thought to be primarily characterized by CD8+ lymphocytes, macrophages, and neutrophils, some patients with COPD may have features of asthma and, subsequently, a component of Th2-mediated airway inflammation. ${ }^{2}$
Pulmonary Diseases and Critical Care Medicine, Department of Medicine, University of North Carolina School of Medicine, CB\# 7020, 130 Mason Farm Rd, 4th Floor Bioinformatics Building, Chapel Hill, NC 27599, USA

$\mathrm{Tel}+|9| 9966253$ |

$\mathrm{Fax}+19199667013$

Email james_donohue@med.unc.edu 
Th2-mediated airway inflammation can be assessed through the measurement of fractional exhaled nitric oxide (FeNO). ${ }^{3}$ Nitric oxide gas is produced in the epithelial cells of the bronchial wall in response to interleukin (IL) 4 and IL13 via the STAT-6 pathway. ${ }^{3}$ Measurement of FeNO is the only clinical test for evaluating Th-2 mediated airway inflammation that can be performed quickly and easily, providing consistent and accurate results in clinical practice at the point-of-care. The measurement of FeNO in human breath with the NIOX MINO ${ }^{\circledR}$ device (AerocrineAB, Solna, Sweden) provides a rapid, noninvasive, and inexpensive tool to assess airway inflammation.

The American Thoracic Society recently published an evidence-based clinical practice guideline that strongly recommends the use of FeNO for the following applications: ${ }^{4}$ 1) diagnosis of eosinophilic airway inflammation in individuals with non-specific lower respiratory symptoms, 2) determining the likelihood of steroid responsiveness in individuals with chronic non-specific lower respiratory symptoms possibly due to airway inflammation, and 3) monitoring eosinophilic airway inflammation in patients with asthma. However, the exact role of FeNO in patients with established COPD remains to be defined. While there have been a number of preliminary studies on measuring FeNO in COPD, literature defining the role of FeNO in patients with established COPD is minimal. Furthermore, many COPD patients have difficulty expectorating sputum and/or can only produce poor quality sputum samples, which are not adequate to accurately quantify eosinophilic cells. The objective of the current study was to characterize FeNO levels that may be indicative of airway inflammation in patients with COPD.

\section{Methods}

\section{Patient population}

Eligible participants included men and women aged 40 years and older with COPD, including chronic bronchitis and emphysema, and/or a mixed diagnosis of asthma/COPD. Participants were excluded from participation in the study if they had other chronic obstructive lung disease including but not limited to cystic fibrosis, bronchiectasis, obliterative bronchiolitis, ciliary dyskinesia, post-viral bronchial hyperresponsive syndrome, vocal cord dysfunction, rhinosinusitis, non-eosinophilic asthma, and reactive airways dysfunction syndrome. Other conditions that excluded patients from participation included pneumothorax, fractured rib(s), or signs of cardiac instability (eg, a recent myocardial infarction, unstable angina, unstable vital signs, or acute shortness of breath, chest tightness, or chest pain). Demographic information, selected medical history information, and baseline characteristics including height, weight, body mass index (BMI), smoking status, pack years of tobacco use, and current medication information were obtained from eligible participants.

\section{Study design}

This was a pilot, observational (no treatment allocation), multicenter, single-visit, outpatient study. This study was conducted at two sites within the University of North Carolina, Chapel Hill, North Carolina, Department of Respiratory and Critical Care Medicine between June 18, 2012 and October 19, 2012. An institutional review board at the study center approved the study protocol and all participants signed a written consent document prior to study enrollment.

\section{Spirometry measurements}

Subsequent to the FeNO measurement, patient spirometry values were collected, according to American Thoracic Society guidelines. ${ }^{5}$ In the event that spirometry preceded the FeNO test, a waiting period of not less than 20 minutes was imposed to separate the two procedures. Parameters collected were forced expiratory volume in 1 second $\left(\mathrm{FEV}_{1}\right)$, forced vital capacity (FVC), forced expiratory flow between $25 \%$ and $75 \%$ of vital capacity $\left(\mathrm{FEF}_{25-75}\right)$, forced expiratory flow at $50 \%$ of vital capacity $\left(\mathrm{FEF}_{50 \%}\right)$, and peak expiratory flow (PEF). The severity of patients' COPD based on spirometry values and Global initiative for chronic Obstructive Lung Disease (GOLD) guidelines was recorded. Once all information had been collected and all procedures had been performed, the patient was discharged from the clinic, as their study participation was completed.

\section{FeNO measurements}

Patients refrained from eating, drinking (except water), and/or smoking for at least 1 hour prior to the FeNO measurement. Training on the use of the device (NIOX MINO ${ }^{\circledR}$; Aerocrine $\mathrm{AB}$ ) to perform FeNO measurements was conducted by the study staff according to the guidelines in the user manual. Patients were instructed to inhale to total lung capacity and then exhale into the device for 10 seconds. A visual incentive was activated upon exhalation to assist patients to maintain a constant flow rate. Exhalations performed at a pressure of 10 to $20 \mathrm{~cm} \mathrm{H}_{2} \mathrm{O}$ were required to maintain a $50 \mathrm{~mL} / \mathrm{second}$ flow rate and resulted in display of a FeNO value. Each patient was allowed up to eight attempts to perform a single valid FeNO measurement. Controls on the device ensured that expiration efforts below the fixed flow rate requirements did not result in display of a FeNO value. 
The FeNO value displayed on the device was not intended for (nor incorporated in) clinical care of the patient during the study visit.

Aerocrine provided training for the principal investigator and available staff on the use of the device during study initiation. All instruments were labeled according to the US Food and Drug Administration guidelines and all devices were returned to the sponsor at the end of the study.

\section{Safety measurements}

Adverse events and serious adverse events were recorded.

\section{Statistical analyses}

As this was an observational study, no formal statistical analyses or hypothesis testing were performed. The safety population included all participants who were enrolled in the study. Adverse events and the ability to perform a FeNO measurement were described in this population. The per protocol population was defined as all participants in the safety population who met all inclusion and exclusion criteria and were also able to perform spirometry and a FeNO measurement. All other data displays and summaries were performed on data from the per protocol population.

\section{Results}

Two hundred participants were screened for this study. Nine patients were excluded from the per protocol population. The primary reason for exclusion from the per protocol population was inability to perform either FeNO or spirometry (eight patients). One additional patient had asthma, but not COPD, and was also excluded. The final per protocol population comprised 191 patients. All 191 patients in the per protocol population completed the study.

Patient demographic information is presented in Table 1. The mean age was 63.9 years (range $42-94$ years) and 58.1\% were women. The vast majority of patients were non-Hispanic (99.0\%) and Caucasian (83.8\%) and predominantly smokers (past smokers-64.9\%; current smokers-30.4\%). Of the past smokers, 96/124 (77\%) reported the time since quitting (mean-13.7 years; range 0-43 years). The most common medications used for pulmonary/allergy conditions were short-acting beta-agonists $(83.8 \%)$, inhaled corticosteroid (ICS) plus long-acting beta-agonist (LABA) bronchodilator combination products $(75.4 \%)$, and long-acting antimuscarinic antagonists (69.6\%) (Figure 1).

There were no reported issues or problems with the use of the device. A total of 194/200 (97.0\%) of the participants had a successful FeNO test.
Table I Patient demographics and baseline characteristics

\begin{tabular}{|c|c|}
\hline Demographic parameter & $\begin{array}{l}\text { Per protocol } \\
\text { population } \\
(\mathrm{N}=191)\end{array}$ \\
\hline Mean age, years (standard deviation [SD]) & $63.9(11.34)$ \\
\hline Range & $42-94$ \\
\hline Female, n (\%) & III (58.1\%) \\
\hline \multicolumn{2}{|l|}{ Primary race, n (\%) } \\
\hline Caucasian & $160(83.8 \%)$ \\
\hline African American & $27(14.1 \%)$ \\
\hline Asian & 0 \\
\hline American Indian or Alaska Native & $2(1 \%)$ \\
\hline Other & $2(1 \%)$ \\
\hline \multicolumn{2}{|l|}{ Ethnicity } \\
\hline Not Hispanic or Latino & $189(99.0 \%)$ \\
\hline Hispanic or Latino & $2(1 \%)$ \\
\hline Mean height, inches (SD) & $65.92(4.059)$ \\
\hline Range & $55.0-79.0$ \\
\hline Mean weight, lbs (SD) & $182.17(46.187)$ \\
\hline Range & $96.0-327.0$ \\
\hline Mean body mass index, $\mathrm{kg} / \mathrm{m}^{2}(\mathrm{SD})$ & $29.47(7.150)$ \\
\hline Range & $15.2-56.5$ \\
\hline \multicolumn{2}{|l|}{ Smoking status, n (\%) } \\
\hline Never smoked & $9(4.7 \%)$ \\
\hline Current smoker & $58(30.4 \%)$ \\
\hline Past smoker & $124(64.9 \%)$ \\
\hline Mean pack years, current and past smokers (SD) & $46.0(29.08)$ \\
\hline Range & $\mathrm{I}-248$ \\
\hline
\end{tabular}
$\mathrm{n}$ refers to the smaller sub-group populations.

\section{Spirometry and FeNO measurements}

Spirometry results are reported in Table 2. As expected in this population, mean $\mathrm{FEV}_{1}$ values indicated obstructive lung disease, with moderate to severe impairment (mean $\mathrm{FEV}_{1} \%$ predicted-53.9\%).

FeNO levels parts per billion (ppb) are summarized by GOLD severity stage in Figure 2. Mean (median, interquartile range $[\mathrm{IQR}])$ FeNO level in the per protocol population was $15.3 \pm 17.18 \mathrm{ppb}$ (12.0 ppb, IQR 8-17); mean values ranged from 3 ppb to $183 \mathrm{ppb}$. Median (IQR) FeNO levels were generally similar by GOLD stage: Stage I, 12 (9.5, 16.75); Stage II, 13 (9, 18.25); Stage III, 11 (7, 15); and Stage IV, 11.5 (6.75, 18.25). Median (IQR) FeNO levels were also similar by sex (male, 12 [8, 21.5]; female, 12 [7.75, 16.25]), race (Caucasian, 12 [8, 17]; African-American, 11 [8, 16.5]); and smoking status (Table 3 ). FeNO levels categorized by low ( $<25 \mathrm{ppb}$ ), intermediate ( $\geq 25$ but $\leq 50 \mathrm{ppb}$ ), and high ( $>50 \mathrm{ppb}$ ) levels are summarized by ICS use, smoking history, and international classification of diseases (ICD)-9 codes in Table 3.

The majority of patients $(89.0 \%)$ had low FeNO levels, regardless of their ICS use, smoking history, or ICD 9 codes. Only 21/191 (11\%) had intermediate or high FeNO levels. 


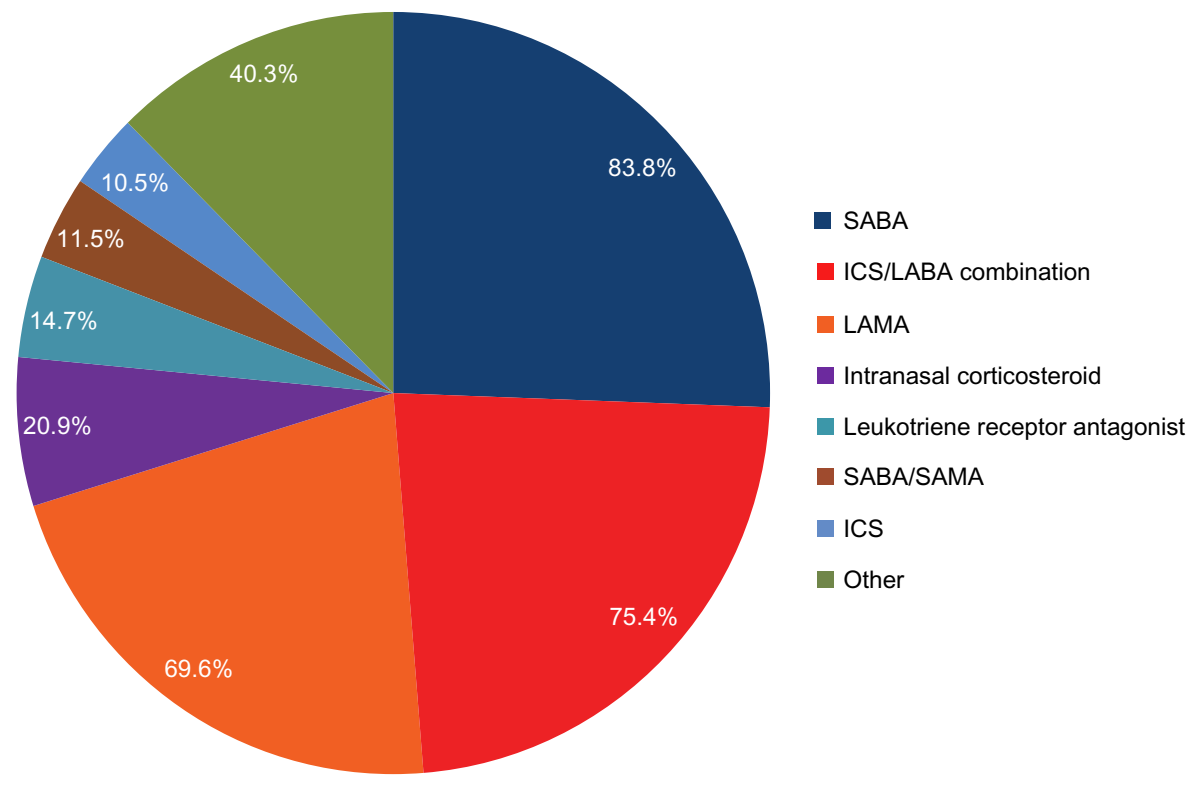

Figure I Pulmonary and allergy medications used in over $10 \%$ of patients.

Note: Patients could be using more than one of the medications.

Abbreviations: SABA, short-acting Beta-2 agonists; LABA, long-acting Beta-2 agonists; ICS, inhaled corticosteroids; LAMA, long-acting muscarinic antagonists; SAMA, short-acting muscarinic antagonists.

A total of $161 / 191$ (84\%) of patients were taking ICS, either alone or in combination with a LABA, though only 61/191 (32\%) had an ICD-9 code that included asthma.

Twenty-one patients had intermediate $(n=16)$ or high $(n=5)$ FeNO levels and 4/5 (80\%) of those with high levels and $7 / 16(44 \%)$ of those with intermediate levels had a

Table 2 Spirometry results for the per-protocol population

\begin{tabular}{|c|c|}
\hline Parameter & Values \\
\hline \multicolumn{2}{|l|}{$\mathrm{FEV}_{1}(\mathrm{~L})$} \\
\hline Mean (SD) & $\mathrm{I} .444(0.6675)$ \\
\hline Range & $0.4 I-3.60$ \\
\hline \multicolumn{2}{|c|}{$\mathrm{FEV}, \%$ predicted } \\
\hline Mean (SD) & $53.9(22.11)$ \\
\hline Range & $9-163$ \\
\hline \multicolumn{2}{|l|}{ FVC (L) } \\
\hline Mean (SD) & $2.680(0.9326)$ \\
\hline Range & $1.05-5.37$ \\
\hline \multicolumn{2}{|l|}{$\mathrm{FEV}_{1} / \mathrm{FVC}$} \\
\hline Mean (SD) & $0.538(0.153)$ \\
\hline Range & $0.182-0.957$ \\
\hline \multicolumn{2}{|c|}{$\mathrm{FEF}_{25 \%-75 \%}(\mathrm{~L} / \mathrm{sec})$} \\
\hline Mean (SD) & $0.759(0.6898)$ \\
\hline Range & $0.12-3.87$ \\
\hline \multicolumn{2}{|l|}{$\mathrm{FEF}_{50 \%}(\mathrm{~L} / \mathrm{sec})$} \\
\hline Mean (SD) & 31.8 (27.78) \\
\hline Range & $3-191$ \\
\hline \multicolumn{2}{|l|}{ PEF (L/min) } \\
\hline Mean (SD) & $244.6(107.27)$ \\
\hline Range & $77-637$ \\
\hline
\end{tabular}

Abbreviations: SD, standard deviation; $\mathrm{FEV}$, forced expiratory volume in I second; FVC, forced vital capacity; FEF, forced expiratory flow; PEF peak expiratory flow. diagnostic ICD-9 code that included asthma. The group with the ICD-9 code that included asthma was found to have the highest FeNO value (mean 20.5 $\pm 27.57 \mathrm{ppb}$ ) compared to mean values of $12.9 \mathrm{ppb}$ in the other ICD-9 groups. There were three patients with intermediate or high FeNO levels who were not taking ICS.

\section{Safety}

Two patients experienced an adverse event that was considered serious, but unrelated to the FeNO maneuver.

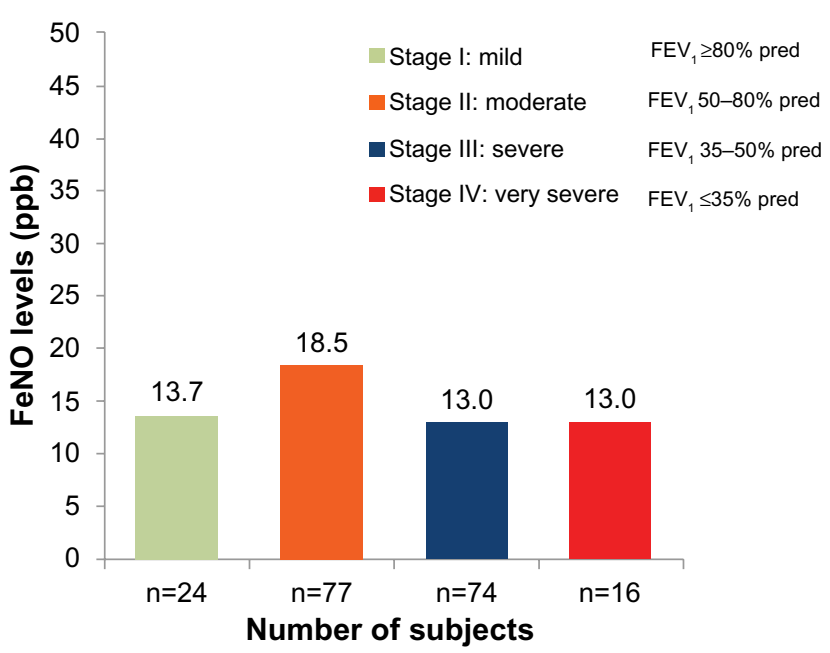

Figure 2 FeNO levels by GOLD stage of COPD severity.

Abbreviations: FeNO, fractional exhaled nitric oxide; GOLD, Global initiative for chronic Obstructive Lung Disease; COPD, chronic obstructive pulmonary disease; $\mathrm{Ppb}$, parts per billion; $\mathrm{FEV}_{1}$, forced expiratory volume in I second; pred, predicted. 
Table 3 FeNO level by inhaled corticosteroid use, smoking status, and ICD 9 code category

\begin{tabular}{|c|c|c|c|c|c|c|c|c|c|}
\hline \multirow{2}{*}{$\begin{array}{l}\text { FeNO } \\
\text { category }\end{array}$} & \multicolumn{2}{|l|}{ ICS use } & \multicolumn{3}{|l|}{ Smoking status } & \multicolumn{3}{|c|}{ ICD 9 code category } & \multirow{2}{*}{$\begin{array}{l}\begin{array}{l}\text { Per } \\
\text { protocol } \\
\text { population } \\
\mathrm{N}=191 \\
\mathrm{n}(\%)\end{array} \\
\end{array}$} \\
\hline & $\begin{array}{l}\text { No } \\
(n=30)\end{array}$ & $\begin{array}{l}\text { Yes } \\
(n=16 I)\end{array}$ & $\begin{array}{l}\text { Never } \\
(n=10)\end{array}$ & $\begin{array}{l}\text { Previous } \\
(n=\mid 23)\end{array}$ & $\begin{array}{l}\text { Current } \\
(n=58)\end{array}$ & $\begin{array}{l}\text { COPD and } \\
\text { asthma } \\
(n=6 I)\end{array}$ & $\begin{array}{l}\text { COPD and } \\
\text { emphysema } \\
(n=50)\end{array}$ & $\begin{array}{l}\text { All other } \\
\text { codes } \\
(n=80)\end{array}$ & \\
\hline$<25 \mathrm{ppb}$ & 27 (90.0\%) & I $43(88.8 \%)$ & $8(80 \%)$ & 105 (85.4\%) & $56(96.6 \%)$ & $50(82.0 \%)$ & $46(92.0 \%)$ & 74 (92.5\%) & $170(89.0 \%)$ \\
\hline $\begin{array}{l}\geq 25 \mathrm{ppb} \\
\text { or } \leq 50 \mathrm{ppb}\end{array}$ & $2(6.7 \%)$ & 14 (8.7\%) & I (I0\%) & $13(10.6 \%)$ & $2(3.4 \%)$ & 7 (I I.5\%) & $4(8.0 \%)$ & $5(6.3 \%)$ & $16(8.4 \%)$ \\
\hline$>50 \mathrm{ppb}$ & I (3.3\%) & $4(2.5 \%)$ & I (I0\%) & $5(4.1 \%)$ & $0(0 \%)$ & $4(6.6 \%)$ & 0 & I (1.3\%) & $5(2.6 \%)$ \\
\hline $\begin{array}{l}\text { Mean FeNO } \\
\text { level, ppb (SD) }\end{array}$ & - & - & - & - & - & $20.5(27.57)$ & $12.9(7.40)$ & $12.9(8.21)$ & $15.3(17.18)$ \\
\hline $\begin{array}{l}\text { Median FeNO } \\
\text { level, ppb (IQR) }\end{array}$ & & & $12(8.75,17.75)$ & $13(9,20.5)$ & $10(7,14.75)$ & - & - & - & $12(8,17)$ \\
\hline
\end{tabular}

Note: $\mathrm{N}$ refers to the per protocol population, upon which analyses were conducted; $\mathrm{n}$ refers to the smaller sub-group populations.

Abbreviations: FeNO, fractional exhaled nitric oxide; ICD, International Classification of Diseases; ICS, inhaled corticosteroid; Ppb, parts per billion; SD, standard deviation; $I Q R$, interquartile range; COPD, chronic obstructive pulmonary disease.

The first patient, a 53-year-old non-smoking African-American woman, experienced headache and chest discomfort, which worsened shortly after leaving the clinic. The second patient, a 46-year-old Caucasian woman, complained of "retaining $\mathrm{CO}_{2}$ ", felt that her movements were slightly jerky, and was unable to perform a FeNO measurement.

\section{Discussion}

The results from this observational study suggest that increases in FeNO do occur in patients with COPD. Although the majority of patients had low levels of FeNO in this study, $11 \%$ of patients had intermediate or high FeNO levels with no overall observable relationship between GOLD classification and FeNO level.

In this study of 191 COPD patients, $61(32 \%)$ had both a diagnosis of asthma and COPD, which is consistent with the number reported by other investigators who suggested that the ACOS exists in $20 \%-33 \%$ of COPD patients and that its prevalence increases with age. ${ }^{6-8}$ Although the percentage of billing codes of asthma was slightly higher in this study than in other studies, the overall findings in the current study are in line with those reported in other epidemiologic studies. ${ }^{6,8}$ This population has traditionally been excluded from clinical trials, but studies have shown that COPD patients can be difficult to differentiate from asthma patients due to their positive bronchodilator responses. ${ }^{9}$ Patients with COPD have long been known to have positive responses to methacholine challenge. ${ }^{10}$

These data suggest that FeNO levels may be helpful in identifying patients with ACOS. FeNO levels in this pilot study were substantially higher in patients with mixed asthma/COPD compared with emphysema alone or COPD without a concurrent diagnosis of asthma or emphysema.
Identifying an eosinophilic inflammatory component in patients with COPD may lead to better treatment choices in this heterogeneous disease. In a prospective study of 49 ex-smoking COPD patients with an acute exacerbation, Soter et al reported that FeNO was a strong predictor of sputum eosinophilia at exacerbation. ${ }^{11}$ There was a significant positive correlation between the percentage of sputum eosinophils and FeNO concentrations both at exacerbation and hospital discharge, regardless of whether or not patients received ICS at hospital admission. Furthermore, COPD patients with eosinophilic airway inflammation responded better to treatment with bronchodilators and corticosteroids compared to patients with predominantly neutrophilic airway inflammation. ${ }^{11}$

Several studies have now shown that patients with COPD who have sputum eosinophilia upon exacerbation may have greater corticosteroid responsiveness. ${ }^{12-14}$ A reduction in eosinophilic airway inflammation has also been shown to reduce the number of future COPD exacerbations. ${ }^{2}$ Other investigators have determined that FeNO levels may be predictive of greater treatment response to corticosteroids and bronchodilator therapy. ${ }^{15,16}$ Antus et al reported that in 58 COPD patients with acute exacerbation, patients with increased FeNO at the time of exacerbation responded better to treatment with corticosteroids and bronchodilators. ${ }^{15}$ Similarly, after 4 weeks of treatment with ICS in a study of 60 ex-smokers with severe COPD, ICS responders had significantly higher baseline FeNO levels compared with non-responders. ${ }^{16}$ Akamatsu et al studied 14 patients with COPD and found that FeNO $>35 \mathrm{ppb}$ and evidence of atopy predicted improvement in $\mathrm{FEV}_{1}$ with ICS/LABA when added to tiotropium. ${ }^{17}$ Zietkowski et al evaluated the usefulness of FeNO in predicting corticosteroid responsiveness 
in 47 patients with COPD. ${ }^{18}$ These investigators found a significant correlation between baseline FeNO and response to corticosteroids following 2 months of treatment. ${ }^{18}$

Taken together, these data suggest that measurement of FeNO may be useful for identifying patients with COPD who will have a beneficial response to corticosteroids. The vast majority of patients in the current pilot study $(75 \%)$ received treatment with an ICS/LABA combination therapy as recommended by COPD standard of care. ${ }^{1}$ Monotherapy with ICS is not currently recommended in the treatment of COPD. However, given that ICS treatment can be costly and may place patients with COPD at greater risk for complications such as pneumonia, osteoporosis, glaucoma, and cataracts, it would be ideal if ICS treatment could be targeted to patients with comorbid Th-2 mediated inflammation. These patients would be more likely to respond to treatment with an ICS or ICS combination therapy.

In this pilot study, many patients who were taking ICS still had elevated levels of FeNO. This observation elicits further study questions: 1) if the ICS dose had been increased in these patients, would FeNO levels or outcomes have been improved? 2) if FeNO levels were not elevated, does the patient truly need ICS therapy? 3) do FeNO levels predict future risk in COPD as they have been shown to predict in asthma ${ }^{19} 4$ ) can that risk be mitigated by adjusting ICS dose in COPD as it can be in asthma? ${ }^{20,21} 5$ ) can FeNO assist in determining medication choices to optimize patient outcomes in COPD? These unanswered questions regarding the role of FeNO measurement in determining a treatment plan for patients with COPD should be addressed in future, well-controlled studies. Another unstudied factor to consider is the effect of smoking on FeNO levels. Smoking is known to suppress exhaled nitric oxide, which may lead to misinterpretation of FeNO levels in COPD. ${ }^{22}$ However, more data are needed to better understand the magnitude of reduction of FeNO that smoking can cause. Also, Barnes et al emphasized the importance of measuring FeNO in patients with COPD exacerbations since insufficient data exist in the assessment of airway inflammation in patients with COPD during exacerbations. ${ }^{23}$

In conclusion, data from this pilot study demonstrated that increases in FeNO values can be observed in patients with COPD. Measurement of FeNO provides the physician with useful information to determine if a patient with COPD has underlying Th-2 mediated inflammation that may indicate ACOS (ie, asthma occurring along with COPD) and may have implications in the management of patients with COPD.

\section{Acknowledgment}

The authors would like to thank Kim Poinsett-Holmes, Pharm D (Poinsett Publications, Inc.) for editorial assistance with the submitted manuscript.

\section{Disclosure}

Dr Donohue is a consultant for Aerocrine Inc. Ms Herje, Dr Crater, and Dr Rickard are employees of Aerocrine Inc.

\section{References}

1 The Global Strategy for the Diagnosis, Management and Prevention of COPD [webpage on the Internet]. Global Initiative for Chronic Obstructive Lung Disease (GOLD) 2013. Available from: http://www. goldcopd.org/. Accessed April 22, 2014.

2. Siva R, Green RH, Brightling CE, et al. Eosinophilic airway inflammation and exacerbations of COPD: a randomized controlled trial. Eur Respir J. 2007;29(5):906-913.

3. Alving K, Malinovschi A. Basic aspects of exhaled nitric oxide. In: Horvath I, de Jongste JC, editors. Exhaled Biomarkers. European Respiratory Society Monographs; 2010:1-31.

4. Dweik RA, Boggs PB, Erzurum SC, et al. An official ATS clinical practice guideline: interpretation of exhaled nitric oxide levels (FENO) for clinical applications. Am J Respir Crit Care Med. 2011;184(5): 602-615.

5. Miller MR, Hankinson J, Brusasco V, et al. Standardisation of spirometry. Eur Respir J. 2005;26(2):319-338.

6. Soriano JB, Davis KJ, Coleman B, Visick G, Mannino D, Pride NB. The proportional Venn diagram of obstructive lung disease: two approximations from the United States and the United Kingdom. Chest 2003;124(2):474-481.

7. Gibson PG, Simpson JL. The overlap syndrome of asthma and COPD: what are its features and how important is it? Thorax. 2009; 64(8): 728-735.

8. Beeh KM, Kornmann O, Beier J, Ksoll M, Buhl R. Clinical application of a simple questionnaire for the differentiation of asthma and chronic obstructive pulmonary disease. Respir Med. 2004;98(7):591-597.

9. Tashkin DP, Celli B, Decramer M, et al. Bronchodilator responsiveness in patients with COPD. Eur Respir J. 2008;31(4):742-750.

10. Ramsdell JW, Nachtwey FJ, Moser KM. Bronchial hyperreactivity in chronic obstructive bronchitis. Am Rev Respir Dis. 1982;126(5): 829-832.

11. Soter S, Barta I, Antus B. Predicting sputum eosinophilia in exacerbations of COPD using exhaled nitric oxide. Inflammation. 2013;36(5): $1178-1185$.

12. Fujimoto K, Kubo K, Yamamoto H, Yamaguchi S, Matsuzawa Y. Eosinophilic inflammation in the airway is related to glucocorticoid reversibility in patients with pulmonary emphysema. Chest. 1999;115(3):697-702.

13. Pizzichini E, Pizzichini MM, Gibson P, et al. Sputum eosinophilia predicts benefit from prednisone in smokers with chronic obstructive bronchitis. Am J Respir Crit Care Med. 1998;158(5 Pt 1):1511-1517.

14. Brightling CE, Monteiro W, Ward R, et al. Sputum eosinophilia and shortterm response to prednisolone in chronic obstructive pulmonary disease: a randomized controlled trial. Lancet. 2000;356(9240):1480-1485.

15. Antus B, Barta I, Horvath I, Csiszer E. Relationship between exhaled nitric oxide and treatment response in COPD patients with exacerbations. Respirology. 2010;15(3):472-477.

16. Kunisaki KM, Rice KL, Janoff EN, Rector TS, Niewoehner DE. Exhaled nitric oxide, systemic inflammation, and the spirometric response to inhaled fluticasone propionate in severe chronic obstructive pulmonary disease: a prospective study. Ther Adv Respir Dis. 2008;2(2):55-64. 
17. Akamatsu K, Matsunaga K, Sugiura H, et al. Improvement of airflow limitation by fluticasone propionate/salmeterol in chronic obstructive pulmonary disease: what is the specific marker? Front Pharmacol. 2011;2:36.

18. Zietkowski K, Kucharewicz I, Bodzenta-Lukaszyk A. The influence of inhaled corticosteroids on exhaled nitric oxide in stable chronic obstructive pulmonary disease. Respir Med. 1999;99(7):816-824.

19. Zeiger RS, Schatz M, Zhang F, et al. Elevated exhaled nitric oxide is a clinical indicator of future uncontrolled asthma in asthmatic patients on inhaled corticosteroids. J Allergy Clin Immunol. 2011;128(2): $412-414$.
20. Syk J, Malinovschi A, Johansson G, et al. Anti-inflammatory treatment of atopic asthma guided by exhaled nitric oxide: a randomized, controlled trial. J Allergy Clin Immunol Pract. 2013;1(6):639-648.

21. Donohue JF, Jain N. Exhaled nitric oxide to predict corticosteroid responsiveness and reduce asthma exacerbation rates. Respir Med. 2013;107(7):943-952.

22. Kharitonov SA, Robbins RA, Yates D, Keatings V, Barnes PJ. Acute and chronic effects of cigarette smoking on exhaled nitric oxide. Am J Respir Crit Care Med. 1995;152(2):609-612.

23. Barnes PJ, Dweik RA, Gelb AF, et al. Exhaled nitric oxide in pulmonary diseases: a comprehensive review. Chest. 2010;138(3):682-692.

\section{Publish your work in this journal}

The International Journal of COPD is an international, peer-reviewed journal of therapeutics and pharmacology focusing on concise rapid reporting of clinical studies and reviews in COPD. Special focus is given to the pathophysiological processes underlying the disease, intervention programs, patient focused education, and self management protocols.

\section{Dovepress}

This journal is indexed on PubMed Central, MedLine and CAS. The manuscript management system is completely online and includes a very quick and fair peer-review system, which is all easy to use. Visit http://www.dovepress.com/testimonials.php to read real quotes from published authors.

Submit your manuscript here: http://www.dovepress.com/international-journal-of-copd-journal 